\title{
Utility of transesophageal echocardiography in identifying spinal canal structures and epidural catheter position: a prospective observational study of intraoperative hemodynamics and postoperative analgesia
}

\section{L'utilité de l'échocardiographie transœesophagienne pour identifier les structures des canaux rachidiens et la position du cathéter péridural: une étude observationnelle prospective sur l'hémodynamie peropératoire et l'analgésie postopératoire}

\author{
Vikash Goswami, MD • Bhupesh Kumar, MD, DM • Goverdhan Dutt Puri, MD, PhD • \\ Harkant Singh, $\mathrm{McH}$ \\ Received: 25 June 2015/Revised: 21 February 2016/Accepted: 5 April 2016/Published online: 11 April 2016 \\ (C) Canadian Anesthesiologists' Society 2016
}

\begin{abstract}
Purpose The aims of this study were to determine the utility of transesophageal echocardiography (TEE) for identifying spinal canal structures and epidural catheter position and to assess the effect of catheter position on intraoperative hemodynamics and quality of postoperative analgesia.

Methods Twenty-six adult patients undergoing thoracic surgery were included in this prospective, observational study. An epidural catheter was inserted $7.5 \mathrm{~cm}$ or more into the thoracic epidural space using a midline approach and a loss-of-resistance technique. A pediatric TEE probe was inserted after induction of general anesthesia. It was used to identify the spinal canal structures, the catheter tip position in the epidural space, and the spread of injected local anesthetic. Intraoperative hemodynamics, postoperative visual analogue scale (VAS) pain scores,
\end{abstract}

Electronic supplementary material The online version of this article (doi:10.1007/s12630-016-0650-x) contains supplementary material, which is available to authorized users.

V. Goswami, MD · B. Kumar, MD, DM ( $ه)$.

G. D. Puri, MD, PhD

Department of Anesthesia and Intensive Care, Post Graduate Institute of Medical Education and Research, Chandigarh 160012, India

e-mail: bhupeshkr@yahoo.com

H. Singh, $\mathrm{McH}$

Department of Cardiothoracic and Vascular Surgery, Post

Graduate Institute of Medical Education and Research,

Chandigarh, India and the need for rescue epidural doses were recorded and compared between groups determined by their catheter position.

Results Two subjects were excluded from the study because of an intrathecally positioned epidural catheter. The remaining 24 subjects were divided into two groups based on TEE-determined epidural catheter position: posterior $(G r-P)$ or lateral $(G r-L)$. Spinal canal structures and the epidural catheter was successfully identified in all patients. The epidural catheter was located posteriorly in 20 (83\%) patients and laterally in four $(17 \%)$ patients. The spread of the local anesthetic was bilateral in all Gr-P patients, whereas it was unilateral in all but one of the Gr-L patients. Compared to Gr-P patients, Gr-L patients had higher heart rates and blood pressures at various time points after local anesthetic administration until the end of surgery $(P=0.02$ to $<0.001)$. Postoperative VAS scores $(P=0.02)$ and the median number of rescue analgesic doses required during the intraoperative and postoperative periods were also higher in $G r-L$ patients $(P<0.001)$.

Conclusion Transesophageal echocardiography reliably identified spinal canal structures and the position of epidural catheters in the epidural space in adult patients. Posteriorly located epidural catheters appear to provide better epidural analgesia than laterally situated catheters.

Résumé

Objectif Les objectifs de cette étude étaient de déterminer l'utilité de l'échocardiographie transœsophagienne (ETO) 
pour identifier les structures des canaux rachidiens et la position du cathéter péridural et d'évaluer l'effet de la position du cathéter sur l'hémodynamie peropératoire et la qualité de l'analgésie postopératoire.

Méthode Vingt-six patients adultes subissant une chirurgie thoracique ont été inclus dans cette étude observationnelle prospective. Un cathéter péridural a été inséré à 7,5 cm ou plus dans l'espace péridural thoracique à l'aide d'une approche médiane et une technique de perte de résistance. Une sonde d'ETO pédiatrique a été insérée après l'induction de l'anesthésie générale. Elle a été utilisée pour identifier les structures des canaux rachidiens, la position de la pointe du cathéter dans l'espace péridural, et la zone de propagation de l'anesthésique local injecté. L'hémodynamie peropératoire, les scores de douleur postopératoire sur une échelle visuelle analogique (EVA) et les besoins en doses péridurales de sauvetage ont été enregistrés et comparés entre les groupes déterminés selon la position du cathéter.

Résultats Deux patients ont été exclus de l'étude en raison de la position intrathécale du cathéter péridural. Les 24 autres patients ont été divisés en deux groupes selon la position du cathéter péridural telle que déterminée par ETO : postérieure $(G r-P)$ ou latérale $(G r-L)$. Les structures des canaux rachidiens et le cathéter péridural ont été précisément identifiés chez tous les patients. Le cathéter péridural était situé postérieurement chez 20 (83\%) patients et latéralement chez quatre (17\%) patients. La propagation de l'anesthésique local était bilatérale chez tous les patients du groupe Gr-P, alors qu'elle était unilatérale chez tous les patients du groupe $G r-L$ sauf un. Par rapport aux patients du groupe Gr-P, les patients du groupe Gr-L ont affiché des fréquences cardiaques et des tensions artérielles plus élevées à différents points dans le temps après l'administration de l'anesthésique local et jusqu'à la fin de la chirurgie $(P=$ $0,02$ à $<0,001)$. Les scores postopératoires sur l'EVA ( $P=$ $0,02)$ et le nombre moyen de doses analgésiques de sauvetage nécessaires pendant les périodes peropératoire et postopératoire étaient également plus élevés dans le groupe $G r-L(P<0,001)$.

Conclusion L'échocardiographie transosophagienne a permis d'identifier de manière fiable les structures des canaux rachidiens et la position des cathéters périduraux dans l'espace péridural chez des patients adultes. Les cathéters périduraux situés postérieurement semblent procurer une meilleure analgésie péridurale que les cathéters situés latéralement.
The practice of thoracic epidural anesthesia has increased significantly over the last decade ${ }^{1}$ because of its numerous beneficial effects, including superior analgesia, attenuation of surgical stress and related immunosupression, ${ }^{2}$ improved pulmonary function, ${ }^{3}$ and potential reduction in overall longer-term outcomes. ${ }^{4}$ Precise positioning of the epidural catheter is thought to be an important requirement for optimal analgesia using minimal drug doses and fewer related complications. ${ }^{5,6}$ One of the major concerns with using epidural anesthesia is the relatively high incidence (up to $30 \%$ in some reports) ${ }^{7}$ of inadequate block, ${ }^{8}$ which is thought most likely to be caused by misplacement of the epidural catheter. ${ }^{9}$

Although surface ultrasonography is a non-invasive tool that can be used in awake patients, its usefulness for thoracic epidural imaging is limited because of the narrow thoracic intervertebral spaces and the oblique trajectory needed for ultrasound imaging in this region. ${ }^{10,11}$ Transesophageal echocardiography (TEE) has the theoretical potential to overcome this age-related barrier by obtaining images of spinal canal stuctures using the intervertebral disc as an acoustic window.

The location of the epidural catheter tip has been shown to affect the distribution of local anesthetics in the epidural space and the resulting quality of analgesia. Indeed, Asato et al. ${ }^{9}$ observed unilateral epidural block when the epidural catheter tip was found in the anterior epidural space or the transforaminal passage. Ueda et al. ${ }^{12}$ similarly observed a unilateral epidural block when the catheter tip was located in the lateral epidural space, rather than in an anterior or posterior location.

The primary aim of the present study was to determine if TEE could be used to correctly identify spinal canal structures (e.g., spinal cord, subarachnoid space, dura mater, epidural space) as well as the position of the epidural catheter in adults. The secondary aim was to determine if the TEE-identified epidural catheter position affects intraoperative hemodynamics and the quality of postoperative analgesia.

\section{Methods}

The study was conducted from July 2013 to December 2014 at our tertiary care hospital. After institutional ethics committee approval (November 2013) and written informed consent, 26 adult ( $>18 \mathrm{yr}$ ) patients with American Society of Anesthesiologists physical status I and II who were scheduled to undergo thoracic surgery requiring thoracotomy for pneumenectomy, lobectomy, 
and/or decortication were enrolled in this prospective observational study. Exclusion criteria included patient refusal, contraindications to epidural blockade (i.e., bleeding diathesis, neurological or spinal disease, local infection), allergy to local anesthetics, history of dysphagia, prior mediastinal radiation, esophageal pathology, and recent upper gastrointestinal surgery.

Under local anesthesia, a 20G epidural catheter was inserted at the T9-T10 or T10-T11 intervertebral space with the patient in a lateral position using a $18 \mathrm{G}$ Tuohy needle and a midline approach with a loss-of-resistance technique. $\mathrm{A} \geq 7.5 \mathrm{~cm}$ long Perifix multiorifice epidural catheter (B. Braun Medical Inc., Bethlehem, PA, USA) was inserted into the epidural space with the aim of advancing the catheter tip to approximately the T4 level. An epidural test dose of $3 \mathrm{ml}$ of $2 \%$ lidocaine with epinephrine ( $5 \mu \mathrm{g} \cdot \mathrm{mL}^{-1}$ was administered to test for intravascular or subarachnoid placement of the catheter. General anesthesia was then induced, and an appropriately sized double-lumen endotracheal tube (DL-ETT) was inserted to allow lung isolation.

A pediatric-size TEE probe (Philips S7; Philips Healthcare, Respironics, Inc., Murryville, PA, USA) was chosen for insertion as it was thought that it would minimize the chance of DL-ETT displacement and any associated tracheobronchial or esophageal injury during frequent TEE probe manipulation. To visualize the spinal canal structures, the TEE probe was placed in the midesophagus to image the heart in a four-chamber view. The probe was then rotated approximately $180^{\circ}$ until the descending thoracic aorta was identified, followed by an additional rotation of $10-20^{\circ}$. The depth setting of the TEE machine was decreased to $3-4 \mathrm{~cm}$, and the gain was increased to optimize image quality. Further subtle advancement or withdrawal of the probe was required to position the transducer at the level of an intervertebral disc because the vertebral bodies block the conduction of ultrasound and prevent imaging of the spinal canal structures. The spinal canal was recognized as a pulsatile structure surrounded by the vertebral structures (Fig. 1). The ease of spinal canal structure identification and epidural catheter position was assessed using a four-point scale as follows: clearly visible, grade 1; visible, grade 2; recognizable but with difficulty, grade 3 ; unrecognizable, grade 4 .

Efforts were made to identify the epidural catheter position inside the epidural space. If the epidural catheter could not be easily visualized, sterile normal saline $(3 \mathrm{~mL})$ was injected through the epidural catheter, visibly expanding the epidural space, allowing confirmation of the catheter tip position. The epidural catheter position in the epidural space was described using a clock face for orientation. It was classified as anterior (between 10 o'clock and 1 o'clock), posterior (between 4 o'clock and 7 o'clock), or lateral (between 1 o'clock and 4 o'clock or between 7 o'clock and 10 o'clock). A mixture of bupivacaine $0.25 \%(4 \mathrm{~mL})$ and fentanyl $\left(1 \mu \mathrm{g} \cdot \mathrm{mL}^{-1}\right)$ was subsequently injected in 2-mL increments, causing expansion of the epidural space, one vertebral space above and below, to confirm the epidural catheter location and pattern of spread of the injectate. If the epidural catheter was not located after a total injection of 7 $\mathrm{mL}$ (one 3-mL saline injection and two 2-mL injections given to identify the catheter one level above and below the insertion site), the procedure was considered a failure. The location of the epidural catheter was determined relative to the T4 level, which was referenced using the TEEidentified origin of the descending thoracic aorta, which is usually located at this level. ${ }^{13,14}$

Spread of the local anesthetic solution in the epidural space was labelled as unilateral when the spread was confined to the same side as the epidural catheter and did not cross the midline. If the spread was observed on both sides of the midline, it was labelled as having bilateral

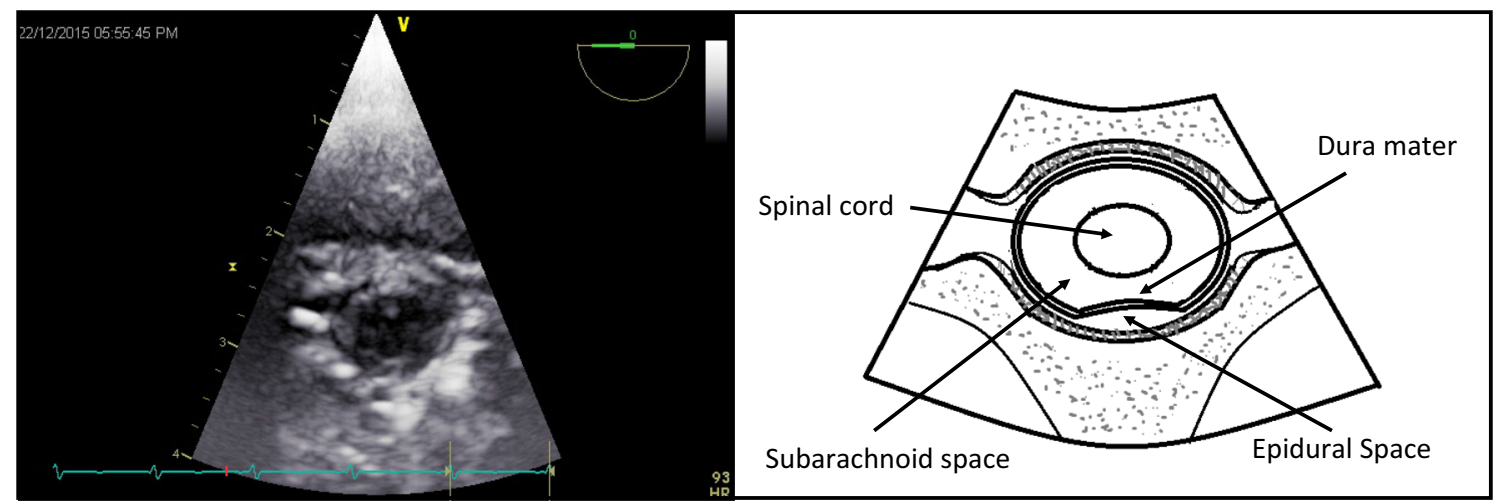

Fig. 1 Dura mater, epidural space, subarachnoid space, and spinal cord are seen in this transesophageal echocardiographic image. The echolucency of the spinal cord is likely due to its relatively high lipid content 
Table Demographic and intraoperative characteristics

\begin{tabular}{llll}
\hline Characteristic & Gr-P $(n=20)$ & Gr-L $(n=04)$ & $P$-value \\
\hline Age (yr) & $43(15)$ & $40(11)$ & 0.66 \\
Sex: Male/ Female & $14 / 6$ & $4 / 0$ & 0.21 \\
Weight (kg) & $58(14)$ & $58(14)$ & 0.99 \\
Height (cm) & $165(7)^{6}$ & $165(6)$ & $2 / 2$ \\
ASA I/II & $4 / 16$ & $368(116)$ & 0.97 \\
Duration of Anesthesia (min) & $295(121)$ & $276(78)$ \\
Duration Of Surgery (min) & $234(105)$ & $5(0)$ & 0.21 \\
Depth Of Epidural Space (cm) & $5(1)$ & $82(3)$ & 0.46 \\
Baseline Heart Rate (beats·min & \\
Baseline Mean Arterial Pressure (mmHg) & $87(10)$ & $90(3)$ & 0.77 \\
\hline ASA A A & $91(9)$ & 0.29 \\
\hline
\end{tabular}

ASA = American Society of Anesthesiologists; Gr-L = lateral epidural catheter position group; $\mathrm{Gr}-\mathrm{P}=$ posterior catheter position group. Values expressed in mean (SD)

spread. A continuous infusion of the bupivacaine/fentanyl mixture was administered through the epidural catheter at $5 \mathrm{~mL} \cdot \mathrm{hr}^{-1}$ throughout the intraoperative period.

Adequacy of the intraoperative analgesia was assessed using hemodynamic responses to the surgical incision. An increase in heart rate (HR) and/or mean arterial pressure (MAP) $>20 \%$ of baseline for more than five minutes during surgery was considered unsatisfactory, reflecting inadequate analgesia. This situation triggered intravenous administration of fentanyl $\left(1 \mu \mathrm{g} \cdot \mathrm{kg}^{-1}\right)$ boluses. The number of these rescue analgesic doses used was recorded.

Epidural catheter insertion was performed by the attending anesthesiologist involved in clinical case management. Acquisition of the TEE image and locating the epidural catheter was performed by a second, independent cardiac anesthesia consultant trained in TEE. An anesthesia resident collected the analgesia and hemodynamic data and was blinded to the location of the epidural catheter. At the end of the surgery, patients were transferred to the intensive care unit (ICU) for postoperative mechanical ventilation (as per our institutional protocol), from which the patient was subsequently weaned at the discretion of the ICU attending anesthesiologist.

During the postoperative period, a continuous epidural infusion of bupivacaine $(0.125 \%)$ and fentanyl $\left(1 \mu \mathrm{g} \cdot \mathrm{mL}^{-1}\right)$ at $5 \mathrm{~mL} \cdot \mathrm{hr}^{-1}$ was administered for $48 \mathrm{hr}$. Postoperative pain was assessed using a $100-\mathrm{mm}$ visual analogue scale (VAS), where $0 \mathrm{~mm}=$ no pain and $100 \mathrm{~mm}$ $=$ worst pain imaginable. A VAS score of $<30 \mathrm{~mm}$ was defined as satisfactory analgesia. If the VAS was $>30 \mathrm{~mm}$, a rescue dose of $5 \mathrm{~mL}$ bupivacaine $(0.125 \%)$ and fentanyl (1 $\mu \mathrm{g} \cdot \mathrm{mL}^{-1}$ ) was administered through the epidural catheter, and intravenous paracetamol $\left(15 \mathrm{mg} \cdot \mathrm{kg}^{-1}\right)$ was given. The numbers of rescue doses needed were recorded. Changes in intraoperative hemodynamics and postoperative VAS score were recorded at four-hour intervals for the first $48 \mathrm{hr}$ after surgery.

Statistical analysis

Statistical analysis was carried out using the Statistical Package for Social Sciences (version 19.0, SPSS Inc., Chicago IL, USA) for Windows. The normality of the data was assessed using the Kolmogorov-Smirnov test. For normally distributed data, the means (standard deviation [SD]) were reported and compared using Welch's $t$ test. For skewed data, the medians (interquartile range [IQR]) were reported and compared using the Mann-Whitney U test. Proportions were compared using the Chi-square or Fisher's exact test, whichever was applicable. For withingroup hemodynamic variables, a repeated-measures analysis of variance was used. When significance was determined, individual time points were tested post hoc using Student's $t$ test with a Bonferroni correction to correct for multiple comparisons. All of the statistical tests were two-sided and were considered significant at $P<$ 0.05 .

\section{Results}

Of the 26 patients enrolled, two were excluded from analysis because of suspicion of an intrathecal position of the epidural catheter (i.e., a bright spot in the subarachnoid space shown by TEE with subsequent clinical confirmation). The intervertebral space at T9-10 was used for catheter insertion in all but one patient, in whom the T10-11 space was used. The posterior catheter position group (Gr-P) and lateral epidural catheter position group (Gr-L) had comparable demographic characteristics, American Society of Anesthesiologists physical status, 


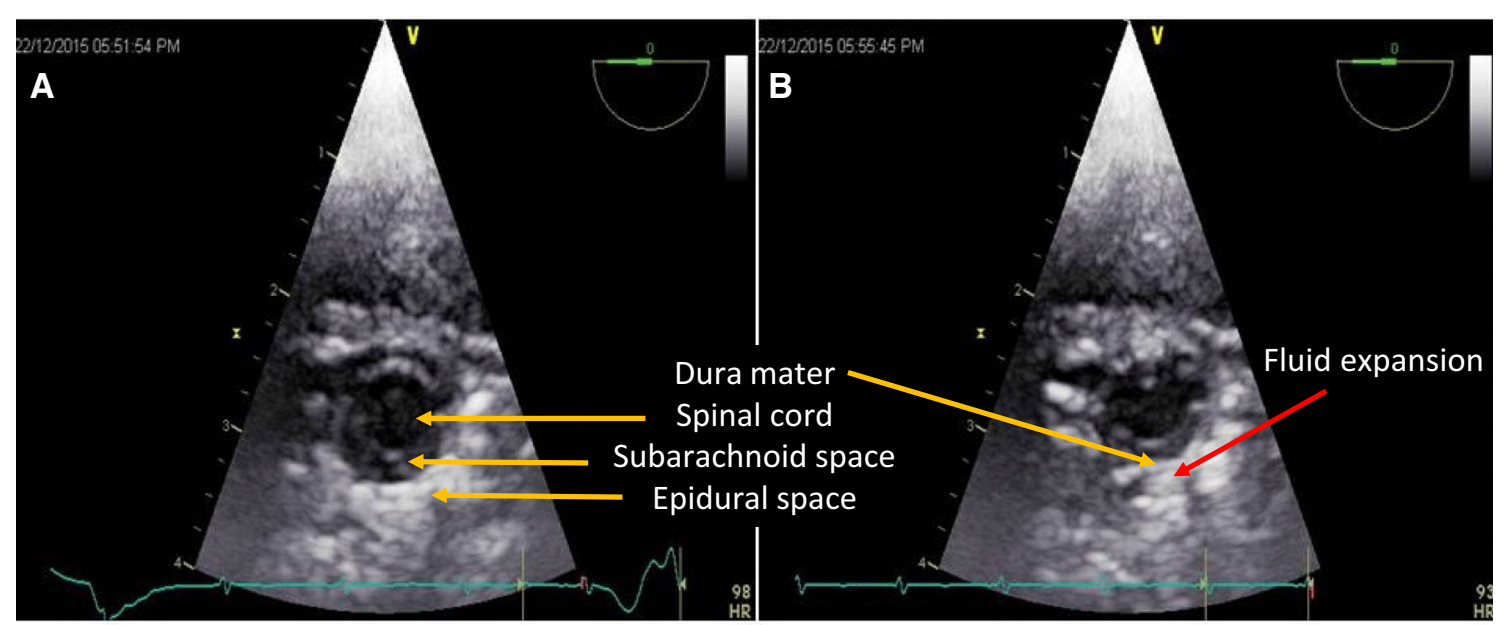

Fig. 2 Transesophageal echocardiographic view of the spinal canal before (A) and after (B) injection via the epidural catheter. After injecting $3 \mathrm{ml}$ of the solution via the epidural catheter, expansion of the epidural space can be seen immediately underneath the dura mater (red arrow)

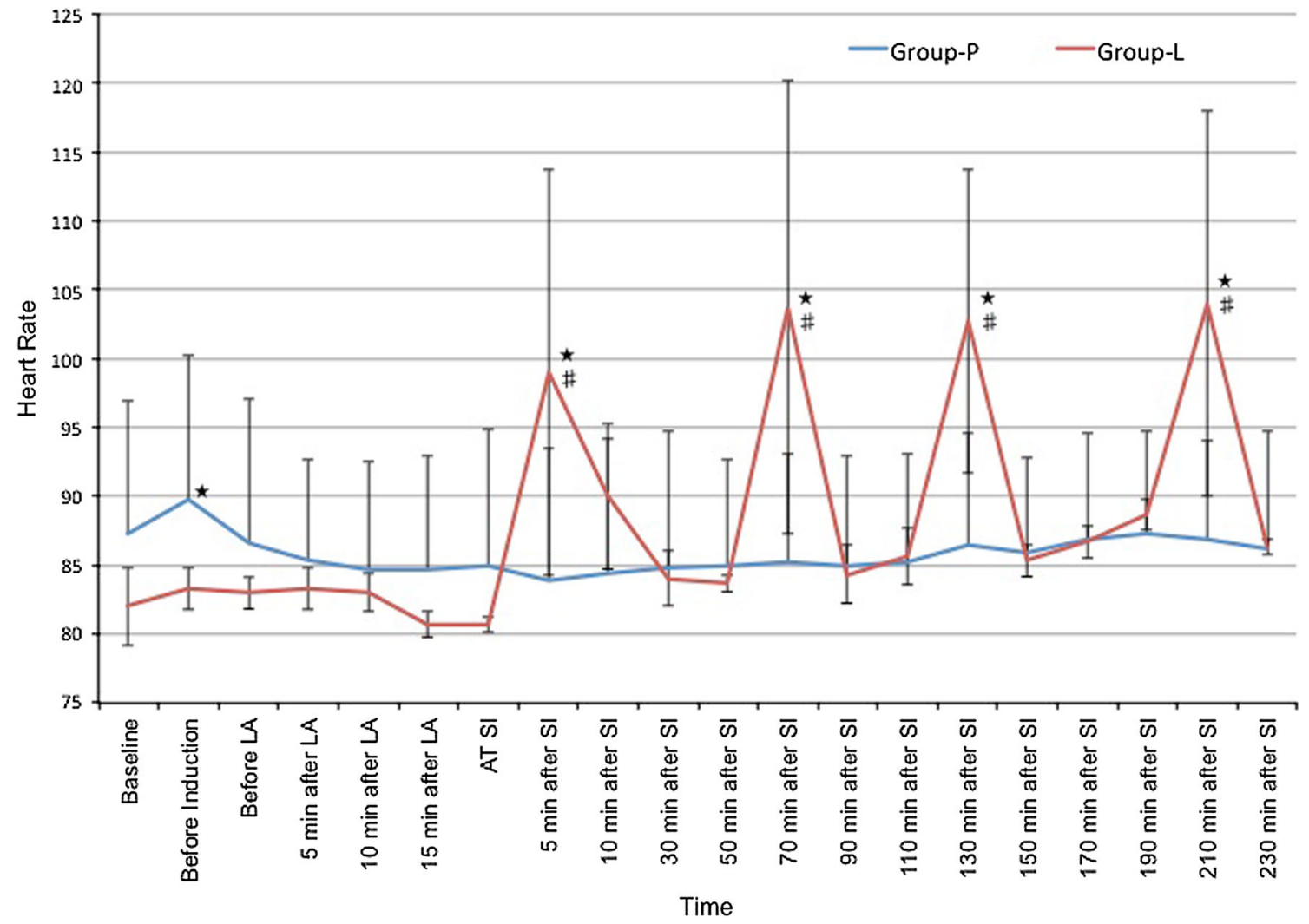

Fig. 3 Changes in heart rate (beats $\mathrm{min}^{-1}$ ) after local anesthetic administration are shown at various time points after the surgical incision during the intraoperative period. Note the recurrent "peaks" of the heart rate in the lateral epidural catheter position patients (Gr-L) that correspond to the duration of action of the rescue "intravenous fentanyl."

duration of anesthesia and surgery, depth of epidural space localization, and baseline hemodynamic characteristics (Table).
This finding highlights the fact that the underlying thoracic epidural was not working. Values are expressed as the mean (SD). $\star$ indicates $P<0.05$ between groups after a Bonferonni correction; \# indicates $>20 \%$ change from baseline. $\mathrm{LA}=$ local anesthetics; $\mathrm{SI}=$ surgical incision

We were able to identify the spinal canal structures and epidural catheter position in all patients. The catheter position could be identified after expanding the epidural 


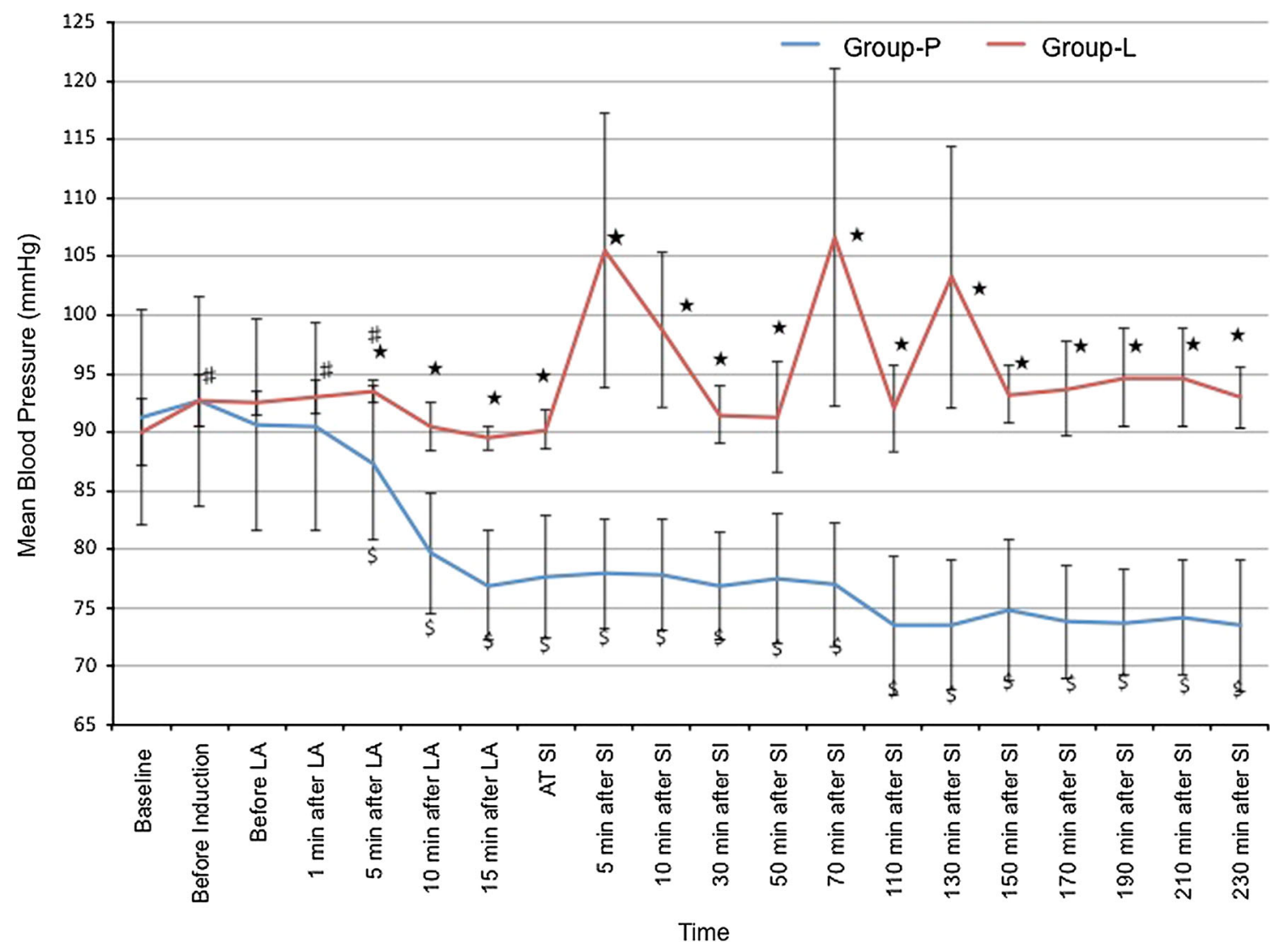

Fig. 4 Changes in mean arterial blood pressure $(\mathrm{mmHg})$ after local anesthetic administration are seen at various time points after the surgical incision during the intraoperative period. Note the recurrent "peaks" of blood pressure in the lateral epidural catheter position patients $(\mathrm{Gr}-\mathrm{L})$ that correspond to the duration of action of the rescue "intravenous fentanyl." This finding highlights the fact that the

space with saline injection through the catheter (Fig. 2, Video [available as Electronic Supplementary Material]). In none of the cases could it be visualized without the saline injection. The ease of identification was grade 1 or 2 in $20(83 \%)$ cases and grade 3 in the remaining four (17\%) cases. The fluid in the epidural space and resulting expansion was located at the T4 level in one (4\%) patient, at the T5 level in $19(79 \%)$ patients, and at the T6 level in the remaining four (17\%) patients. The epidural catheter location was identified in the posterior position in $20(83 \%)$ patients and in the lateral position in four $(17 \%)$ patients.

The epidural catheter was located on the opposite side of the surgical incision in all of the Gr-L patients. The spread of local anesthetic in the epidural space was bilateral in all of the Gr-P patients but in only one Gr-L patient.

Regarding the hemodynamic endpoints, the HR before surgical incision was similar in the two groups except before induction of anesthesia, where it was higher in the Gr-P patients $(P=0.01)$. At five, 70, 130, and 210 min after underlying thoracic epidural was not working. Values are expressed as the mean (SD). $\star$ indicates $P<0.05$ between the two groups; $\$$ indicates $P<0.05$ compared to baseline in the Gr-P patients; \# indicates $P<0.05$ compared to baseline in the Gr-L patients after a Bonferonni correction. $\mathrm{LA}=$ local anesthetic; $\mathrm{SI}=$ surgical incision

surgical incision, the HR was significantly higher in Gr-L patients than in Gr-P patients $(P=0.04,0.02,0.02$ and 0.01 , respectively). These changes in HR were $>20 \%$ from baseline values at similar time points in the Gr-L patients, whereas the HR remained within $20 \%$ of baseline in the Gr-P patients (Fig. 3).

The MAP was significantly higher in the Gr-L patients than in the Gr-P patients beginning five minutes after local anesthetic administration and lasting until the end of surgery $(P=0.02$ at ten minutes after local anesthetic administration; $p=0.01$ at five, 70 , and $130 \mathrm{~min}$ after surgical incision; and $P<0.001$ at the rest of the time points) (Fig. 4). Compared to baseline values, Gr-P patients showed a significant decrease in MAP before induction of anesthesia and from five minutes after local anesthetic administration until the end of surgery $(P<$ 0.01). The Gr-L patients showed a significant rise before induction of anesthesia $(P=0.03)$ and at one minute $(P=$ $0.04)$ and five minutes $(P=0.03)$ after local anesthetic administration (Fig. 4). These changes in MAP, however, 
Fig. 5 Postoperative visual analogue score (VAS) for pain in patients undergoing thoracotomy with epidural anesthesia Values are expressed as the mean (SD). $\star$ indicates $P<0.05$ between the two groups after a Bonferonni correction

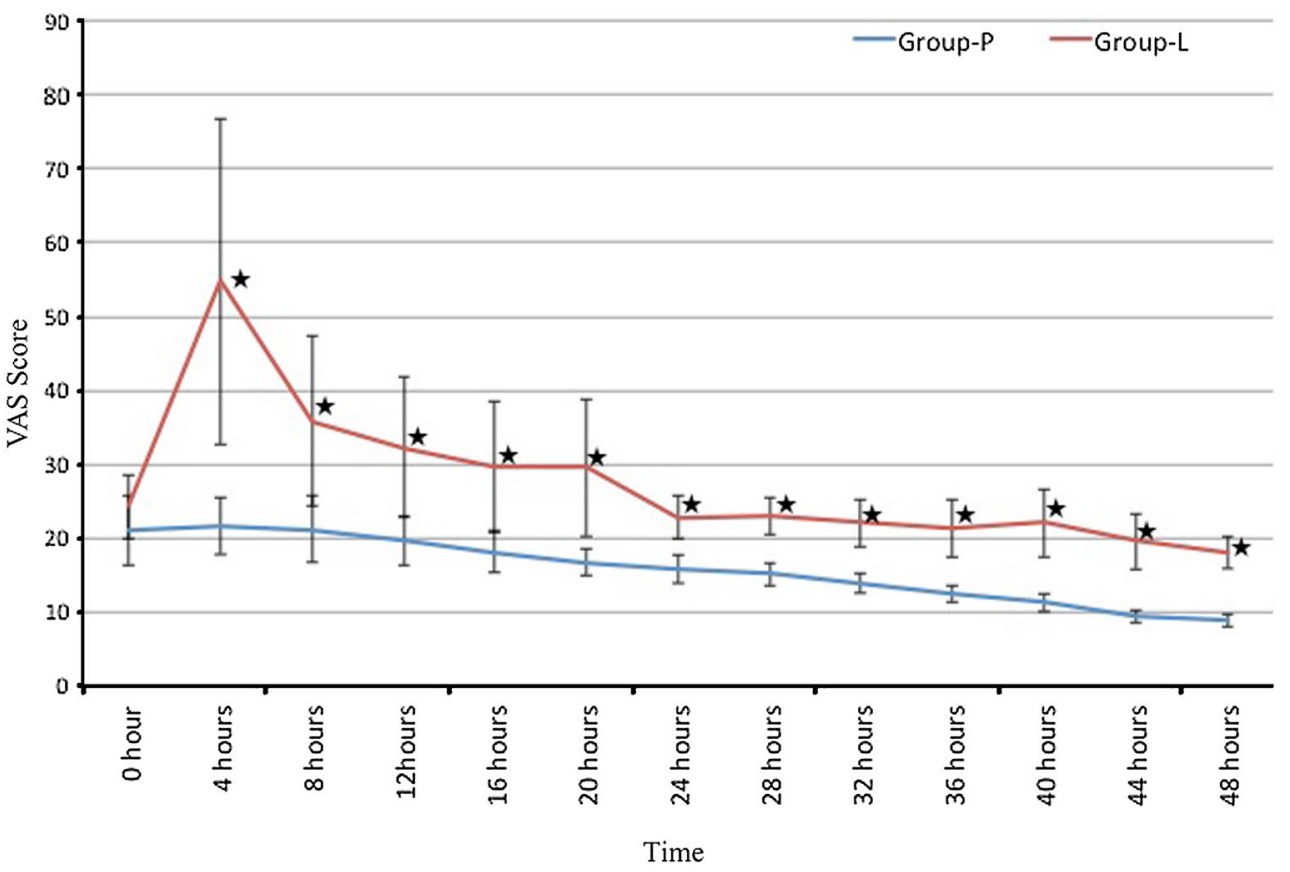

remained within $20 \%$ of the baseline values in both the groups.

The VAS was significantly higher in the Gr-L patients than the Gr-P patients from four hours to $48 \mathrm{hr}$ after surgery $(P<0.02)$ (Fig. 5). The median [IQR] number of rescue analgesic doses required was also significantly higher in the Gr-L patients (4 [5]) during both intraoperative and postoperative (3[2]) periods compared with those for the Gr-P patients $(0[0])(P<0.001)$. All of the patients who required rescue analgesic during the intraoperative period also required it during the postoperative period.

\section{Discussion}

The results of this study showed that spinal canal structures and the epidural catheter position could be reliably identified in adult patients using TEE. In addition, posteriorly positioned epidural catheters resulted in bilateral spread of local anethetics and more optimal hemodynamic responses to surgical stimulation than the laterally positioned catheters, which produced unilateral spread and unsatisfactory hemodynamic responses. The VAS scores and number of rescue analgesic doses required were also higher in patients with the laterally positioned epidural catheters.

Previous reports of incidental TEE imaging of the spinal cord during TEE examination of the descending thoracic aorta described the cross-sectional spinal cord image as a "bull's eye."15-17 Our report suggests that it can be imaged easily when it is sought deliberately. The image is lost with up or down movement of the probe because of interference from the bony vertebral bodies. This feature assisted in determining the position of the epidural catheter in the current study by counting the number of vertebral spaces above or below the reference T4 level (i.e., the origin of the descending thoracic aorta). However, there may be anatomical variations and/or unfolding of the aorta in older patients that could affect this positioning technique.

There are a number of reports of spinal cord imaging using TEE, but none used it to locate thoracic epidural catheter positioning, thus making our study unique. Our spinal cord imaging findings per se are consistent with those of Godet et al. ${ }^{18}$ who first described the ability of TEE to visualize the spinal canal. They reported successful imaging in $100 \%$ of cases, identifying $7.5 \pm 2.3$ spinal segments in the thoracic region. Mugge et al. ${ }^{19}$ also reported successful imaging of at least two spinal segments in $100 \%$ of cases, identifying three to five segments in $75 \%$ and more than five segments in $25 \%$ of cases. Ueda et al. ${ }^{12}$ reported visualizing spinal canal structures in all of their 12 pediatric cases. Funck et al. $^{20}$ reported $88 \%$ success and were able to visualize five (range 1-11) sequential segments in the thoracolumbar region. This relatively lower success rate was attributed to the older age of their patients (mean age, $56 \mathrm{yr}$; range 22-79 yr). A further unique aspect to our study was that prior studies did not report any qualitative information on the ease of identification. Although we had $100 \%$ success in visualizing the spinal canal and its structures, we found that it was either clearly visible (grade 1 ) or visible (grade 2) in $83 \%$ of cases.

Ueda et al. ${ }^{12}$ reported visualizing the caudal epidural catheter in real time while it was being inserted through the 
caudal canal in pediatric patients. We did not identify the epidural catheter directly but, rather, indirectly by expanding the epidural space following a 3-mL saline injection via the catheter (Fig. 2). This difference might be related to differences in the patients' ages and the absence of real-time observation (of the actual threading of the epidural catheter) in the present study. Also, the appearance of the expansion of the epidural space during injection may somewhat misrepresent actual placement of the epidural catheter tip as there could be considerable cephalad movement of the injectate. However, cephalad spread is likely to be less with the small volumes of injectate used in the current study.

After passing through a Tuohy needle, an epidural catheter does not always follow a straight path in the epidural space. Indeed, Lim et al. ${ }^{21}$ reported that in $65 \%$ of cases the tip of catheter deviated laterally immediately after leaving the needle tip. A lateral position of the epidural catheter has been reported in $33-90 \%$ of cases. ${ }^{12,22}$ We observed this situation in $16 \%$ of cases. This difference may be related to the different method of detection used in the present study.

Hogan et al..$^{23}$ used computed tomography to observe epidural catheters, reporting that they were mostly positioned lateral to the dura in the intervertebral foramina. They concluded that far-lateral positioning of an epidural catheter is a more common cause for asymmetrical block than anatomical barriers to solution spread. Our study also demonstrated "unilateral" spread of the local anesthetic with a laterally positioned catheter. Interestingly, one patient with a laterally positioned catheter tip showed bilateral spread of the local anesthetic. In this case, the epidural catheter was located at about the 4 o'clock position, whereas the rest were at far lateral positions ( 3 o'clock or beyond).

Asato et $a l .{ }^{9}$ found that an anteriorly located epidural catheter tip results in inadequate epidural analgesia. Lateral and far-lateral positioning of the epidural catheter has also been associated with inadequate epidural analgesia. ${ }^{12,23}$ Our results agree with those of previous reports that associated the laterally situated catheter with inadequate epidural analgesia. In addition, in our study the catheter was located on the side opposite the site of the surgical incision, which may have contributed to the inadequate effect of the epidural drug. Gielen et al. ${ }^{22}$ reported that sympathetic blockade did not correlate with catheter position. This difference in findings may be due to the large volume of local anesthetic administered into the epidural space in their study. Hogan et al. ${ }^{23}$ also showed that, with larger volumes injected, more uniform spread is seen in the epidural space. We administered a $3-\mathrm{mL}$ bolus followed by continuous infusion, which might have resulted in unilateral spread in patients with laterally positioned catheters.
To our knowledge, no previous study has evaluated the effect of different locations of the epidural catheter on VAS scores and the rescue analgesic requirement. Our study showed trends for higher VAS scores and higher rescue analgesic requirements during the intraoperative and postoperative periods, suggesting inadequate epidural analgesia with laterally positioned catheters. To address the question of whether larger volumes of local anesthetic administration would have led to bilateral spread and symmetrical analgesia needs to be answered with a specifically designed study.

There were some limitations in our study. The utility of intraoperative TEE to guide identification of the epidural catheter was somewhat limited as the catheter was already in position by the time the TEE was performed, and thus repositioning the catheter was impossible. However, there may be utility in knowing whether it should be replaced postoperatively. Another limitation was that no "gold standard" technique was used to confirm the precise location of the epidural catheter shown by TEE. Also, there could be a variation in the reference point (origin of the descending thoracic aorta) used in the study. Hence, unless one can image the actual point of entry of the catheter, TEE provides only an approximation at best. Lastly, the sample size was too small to make any confident conclusions about the impact of the epidural solution spread pattern on the quality of epidural analgesia.

In conclusion, TEE seems to identify the spinal canal structures and the location of thoracic epidural catheters with consistency. Using this technique may provide useful information on the effectiveness (hemodynamic and pain scores) of thoracic epidural analgesia.

Funding None.

Conflicts of interest None declared.

Author contributions Vikash Goswami was involved in data acquisition, data analysis, drafting, and approving the manuscript. Bhupesh Kumar was involved in conceptualizing and designing the study, data analysis, critical revision, and final approval of the manuscript. Goverdhan Dutt Puri was involved in designing the study, critical revision, and final approval of the manuscript. Harkant Singh was involved in conceptualization, critical revision, and final approval of the manuscript.

Editorial responsibility This submission was handled by Dr. Hilary P. Grocott, Editor-in-Chief, Canadian Journal of Anesthesia.

\section{References}

1. Pennefather SH, Gilby S, Danecki A, et al. The changing practice of thoracic epidural analgesia in the United Kingdom: 1997-2004. Anaesthesia 2006; 61: 363-9. 
2. Peutrell JM, Lonnqvist PA. Neuraxial blocks for anaesthesia and analgesia in children. Curr Opin Anaesthesiol 2003; 16: 461-70.

3. Panaretou V, Toufektzian L, Siafaka I, et al. Postoperative pulmonary function after open abdominal aortic aneurysm repair in patients with chronic obstructive pulmonary disease: epidural versus intravenous analgesia. Ann Vasc Surg 2012; 26: 149-55.

4. Chen WK, Ren L, Wei Y, et al. General anesthesia combined with epidural anesthesia ameliorates the effect of fast-track surgery by mitigating immunosuppression and facilitating intestinal functional recovery in colon cancer patients. Int $\mathrm{J}$ Colorectal Dis 2015; 30: 475-81.

5. Berde $C B$. Convulsions associated with pediatric regional anesthesia. Anesth Analg 1992; 75: 164-6.

6. Larsson BA, Lonnqvist PA, Olsson GL. Plasma concentrations of bupivacaine in neonates after continuous epidural infusion. Anesth Analg 1997; 84: 501-5.

7. Ready LB. Acute pain: lessons learned from 25,000 patients. Reg Anesth Pain Med 1999; 24: 499-505.

8. Hermanides J, Hollmann MW, Stevens MF, Lirk P. Failed epidural: causes and management. Br J Anaesth 2012; 109: 14454.

9. Asato $F$, Goto $F$. Radiographic findings of unilateral epidural block. Anesth Analg 1996; 83: 519-22.

10. Rapp HJ, Folger A, Grau T. Ultrasound-guided epidural catheter insertion in children. Anesth Analg 2005; 101: 333-9.

11. Willschke H, Marhofer P, Bosenberg A, et al. Epidural catheter placement in children: comparing a novel approach using ultrasound guidance and a standard loss-of-resistance technique. Br J Anaesth 2006; 97: 200-7.

12. Ueda K, Shields BE, Brennan TJ. Transesophageal echocardiography: a novel technique for guidance and placement of an epidural catheter in infants. Anesthesiology 2013; 118: 219-22.

13. William PL, Warwick $R$, Dyson M, Bannisten LH. Gray's Anatomy, 37th edition, NY: Churchill Livingstone; 1989 (chapter-6): 732 .
14. Chaurasia BD. Human Anatomy (Regional and Applied Dissection and Clinical) 4th Edition, Vol.1, New Delhi, CBS Publishers \& Distributors; 2004 (chapter-19): 262.

15. Nath MP, Gupta S, Kiran U, Chauhan S, Dhawan N. Spinal cord imaging by transesophageal echocardiography: a new modality of monitoring. Acta Anaesthesiol Taiwan 2011; 49: 114-5.

16. Chitilian HV, Alston TA, Avery EG. Transesophageal echocardiographic bull's eye. J Cardiothorac Vasc Anesth 2006; 20: 894-5.

17. Lohser J. Spinal cord imaging by transesophageal echocardiography. J Cardiothorac Vasc Anesth 2009; 23: 442-3.

18. Godet G, Couture P, Ionanidis $G$, Gosgnach $M$, Kieffer E, Viars $P$. Another application of two-dimensional transesophageal echocardiography: spinal cord imaging. A preliminary report. J Cardiothorac Vasc Anesth 1994; 8: 14-8.

19. Mugge A, Konitzer M, Gaab M, Haubitz B, Daniel WG. Ultrasound imaging of the spinal cord via the esophagus in conscious patients: initial experience. J Clin Ultrasound 1991; 19: 187-90.

20. Funck M, Schneider B, Igloffstein J, Vogel P, Hanrath $P$. Transesophageal ultrasonography of the spinal canal (German). Dtsch Med Wochenschr 1989; 114: 529-33.

21. Lim YJ, Bahk JH, Ahn WS, Lee SC. Coiling of lumbar epidural catheters. Acta Anaesthesiol Scand 2002; 46: 603-6.

22. Gielen MJ, Slappendel R, Merx JL. Asymmetric onset of sympathetic blockade in epidural anaesthesia shows no relation to epidural catheter position. Acta Anaesthesiol Scand 1991; 35: 81-4.

23. Hogan $Q$. Epidural catheter tip position and distribution of injectate evaluated by computed tomography. Anesthesiology 1999; 90: 964-70. 